\title{
Moving the Coal-posts: Ottawa's Wrong Turn on Carbon Pricing for Electricity Generation
}

by

Grant Bishop

- Curbing the greenhouse gas emissions of electricity generators is the target of impending regulations from Ottawa. The federal government has proposed regulations that will see power facilities pay a carbon price on the portion of emissions that exceed a benchmark level. However, the proposed benchmark is fuel-specific, differing by whether coal or natural gas is used to produce the power. This creates an unlevel playing field.

- Ottawa's proposed fuel-specific benchmark will have the effect of reducing the average carbon cost for coal plants and stands in contrast to Alberta's approach, which uses a uniform benchmark to allocate credits whatever fuel is used to generate electricity, from coal and natural gas, to wind, hydro and solar.

- Differentiating output-based standards based on fuel undermines the principle of an economy-wide carbon price by effectively prescribing different carbon costs for producers of the same product - electricity.

- Relative to a uniform standard for output-based allocations, Ottawa's fuel-specific benchmark risks distorting the order in which plants are dispatched - potentially pushing high-emission coal plants ahead of lower-emission natural gas plants.

- Unlike Alberta's approach, Ottawa's proposed output-based pricing system for electricity does not allocate credits to zero-emission electricity producers (e.g., hydro, wind and solar) and will diminish incentive for new investment in renewable generation.

The other shoe has yet to drop in the federal government's carbon-pricing "backstop," which was enacted in June 2018 under the Greenhouse Gas Pollution Pricing Act. The backstop applies to designated provinces where the federal Minister of the Environment and Climate Change Canada

The author thanks Farah Omran, Jan Carr, Patrick Dalzell, Jason Dion, Sara Hastings-Simon, Brian Livingston, Dwight Newman, Blake Shaffer, Grant Sprague, anonymous reviewers and members of the C.D. Howe Institute's Energy Policy Council for comments on an earlier draft. The author retains responsibility for any errors and the views expressed. 
(ECCC) determines the carbon price insufficient. The backstop consists of two components: (1) a fuel charge that applies to the purchase of fuels that emit greenhouse gases; and (2) an output-based pricing system (OBPS) for large industrial emitters.

Part 1 (the fuel charge) came into effect for designated provinces on April 1, 2019. While key details of Part 2 (the OBPS) remain yet to be finalized through regulations, the OBPS will apply from January 2019 onwards. Once OBPS regulations are finally promulgated, ECCC proposes to apply these retroactively. ${ }^{1}$ The ECCC Minister has designated that the OBPS will apply to all specified emitters in Ontario, Manitoba and New Brunswick. Although Saskatchewan was also to be a designated province, the federal OBPS will not apply generally to Saskatchewan large emitters; however, the federal OBPS will apply to electricity generation in Saskatchewan. ${ }^{2}$ If Alberta's new government eliminated the province's present carbon pricing system, Alberta would become non-compliant and presumably be designated for imposition of the federal "backstop".

Under the OBPS, facilities will pay a carbon price on the portion of emissions that exceed a benchmark emission intensity (i.e., tonnes of $\mathrm{CO}_{2}$ equivalent per unit of output). That is, a facility will receive an allocation of emissions credits based on its output of a given product at the benchmark and pay for greenhouse gases (GHGs) only to the extent that its GHG emission intensity exceeds the benchmark.

In broad terms, the design of the federal backstop mirrors the carbon-pricing system put in place in Alberta under the Climate Change Leadership Plan and the associated Carbon Competitiveness Incentive Regulation (CCIR), which provides Albrta's framework for output-based pricing of GHGs from large emitters (see overview in Box 1). However, the proposed details of Ottawa's output-based carbon pricing for the electricity sector will depart significantly from Alberta's approach.

For carbon pricing to efficiently reduce a sector's GHG emissions, the same prices and offsets should apply to producers of the same product. In contrast, the federal OBPS for electricity discriminates between power generators based on the fuel used by a facility to produce power. Relative to Alberta's CCIR design, the proposed federal OBPS for electricity would discourage investment in renewable generation and distort the order in which power facilities are dispatched (i.e., produce electricity for the grid), favouring more GHG-intensive electricity.

Ottawa has lagged on finalizing key details of its output-based pricing system. Although the federal OBPS applies from January 1, 2019 onwards in designated provinces, the federal government has yet to promulgate (i.e., put into effect) the necessary regulations to establish benchmark emission intensity that will face large emitters of greenhouse gases. Nonetheless, Ottawa issued a regulatory proposal document for its output-based carbon pricing system on December 20, 2018. ${ }^{3}$ Under the regulatory proposal, the federal government will

1 See: Environment and Climate Change Canada. (2018) Notice of intent to make regulations under part 2 of the Greenhouse Gas Pollution Pricing Act. Available online: https://www.canada.ca/en/environment-climate-change/ services/climate-change/pricing-pollution-how-it-will-work/output-based-pricing-system/notice-intent.html.

2 On March 19, 2019 the federal Department of Finance released regulatory proposals respecting the integration of the Saskatchewan output-based performance standards system with the federal fuel charge. These provisions are proposed to apply starting January 1, 2019. See: https://www.fin.gc.ca/n19/data/19-023_1-eng.asp.

3 Environment and Climate Change Canada. (2018) Proposal for the Output-Based Pricing System Regulations. December 20. Available online at: https://www.canada.ca/en/environment-climate-change/services/climate-change/ pricing-pollution-how-it-will-work/output-based-pricing-system/proposal-regulations.html. 
differentiate the GHG emissions intensity benchmark for assigning allocations based on the fuel type used to generate electricity. Specifically, coal-fired power plants will receive a greater allocation per MWh than will natural gas-fired power plants, and zero-emission generation (e.g., hydro and wind) will not receive any allocation. The result of differentiating the benchmark is that a more GHG-intensive coal-fired power plant may pay less for each tonne of GHG emissions than a natural-gas fired power plant.

Under Ottawa's proposed regulations, coal generation plants would be allocated credits for 2019 based on output-based standard of 800 tonnes per GWh, while natural gas plants would be credited at 370 tonnes per GWh (this is a "best-gas" benchmark, which is equivalent to best-in-class GHG emission intensity for a natural gasfired power plant). Figure 1 shows the annual benchmark emission intensity for coal and natural gas generation under the proposed federal OBPS, as well as the uniform benchmark applicable to all electricity under the Alberta CCIR. The proposed federal regulations indicate that the coal-specific benchmark is to converge with that for natural gas by 2030 . However, in the near-term, the separate benchmarks will dramatically decrease the average carbon costs that coal generation will face - and dampen incentives to reduce emissions.

Moreover, unlike the system for assigning output-based allocations in Alberta, zero-emission electricity generation will not receive any output-based allocation: this means that investing in renewable generation would be comparatively less attractive under the federal backstop.

Ottawa's approach undercuts the concept of a single economy-wide carbon price and the economic rationale behind carbon pricing (i.e., efficient distribution of reductions with all emitters internalizing the social cost of their emissions). While the federal government is likely concerned to avoid spikes in power prices in those provinces where power generation currently relies on coal, Ottawa risks distorting provincial power markets and investment incentives by differentiating carbon costs for producers of the same product. Rather than a highly arbitrary and distortionary fuel-specific approach, the federal government could more transparently address distributional concerns related to power prices with directed transfers to households (as it has done with the recycling of fuel charge revenues). Competitiveness concerns could be addressed by incorporating carbon costs for electricity into the output-based pricing for specific trade-exposed industries (see Box 1).

This E-Brief proceeds by: (1) providing a brief context for emission intensity in power generation across Canada; (2) illustrating the impact of a coal-specific standard on the carbon costs faced by generation facilities; and (3) explaining how the proposed fuel-specific electricity benchmark would (a) distort dispatch of power facilities and (b) discourage investment in renewable generation.

\section{GHG Emissions Intensity in Canadian Power Generation}

The composition of power generation differs widely between provinces. Figure 2 shows the share of generation in selected provinces by fuel source. Hydro power is dominant in B.C., Manitoba, Quebec and Newfoundland and Labrador. PEI is effectively entirely reliant on wind. Ontario is highly reliant on nuclear power and, to a lesser extent, New Brunswick also depends on nuclear generation. Coal power provides much of the power generation in Alberta, Saskatchewan and Nova Scotia, as well as contributing significantly to supply in New Brunswick.

The differences in the composition of generation between provinces result in varying amounts of GHG emissions relative to the power generated in each province - the so-called GHG emission intensity for electricity, typically measured in tonnes of $\mathrm{CO}_{2}$ equivalent per MWh of power. Figure 3 shows the overall GHG emission intensity for electricity in each province for 2010 and 2016 and also shows the contribution to emission intensity of power generation from each of coal, natural gas and other fuel types. Given the relatively higher GHG emission 


\section{Figure 1: Benchmark GHG Emission Intensity for Electricity under Proposed Federal}

\section{OBPS and Alberta CCIR}

Benchmark

GHG Emission Intensity

$\mathrm{CO}_{2}$ Eq. Tonnes/GWh

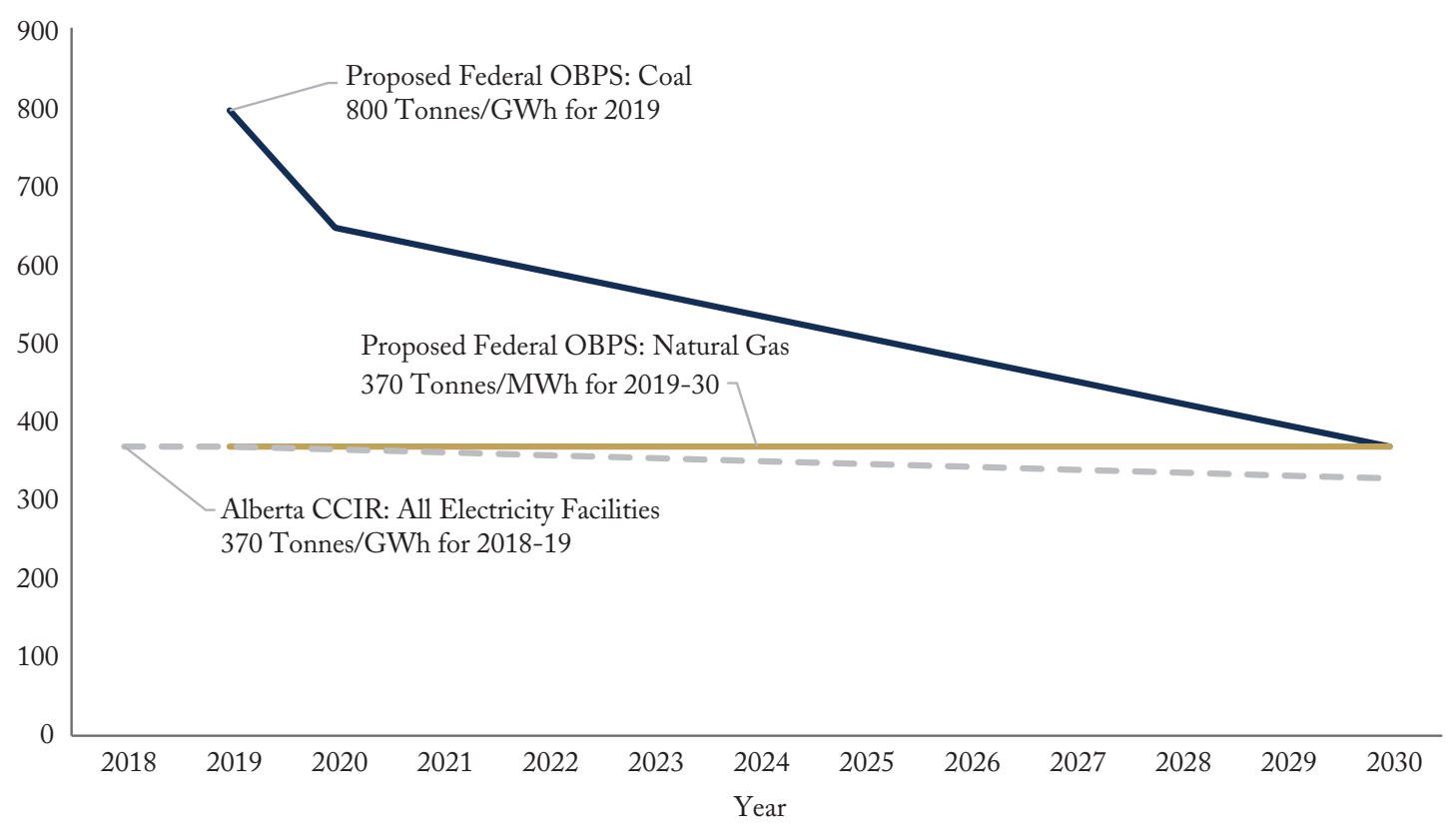

- Proposed Federal OBPS: Coal

_ Proposed Federal OBPS: Natural Gas

- Alberta CCIR: All Electricity Facilities

Source: Alberta CCIR, Federal OBPS Regulatory Proposal.

intensity of coal-fired generation, the reliance on coal for power in Nova Scotia, New Brunswick, Saskatchewan and Alberta results in significant GHG emissions per MWh in those provinces. In contrast, Ontario's phase-out of coal and low reliance on natural gas for power generation results in very low GHG emission intensity. In provinces with hydro power resources, GHG emission intensity for electricity is negligible.

However, among provinces with high reliance on coal and natural gas, the average GHG emission intensity of coal and natural gas power generation also varies. Figure 4 shows the average GHG emission intensity for power generation by coal and natural gas facilities in Alberta, Saskatchewan, New Brunswick and Nova Scotia relative to the 2019 benchmarks for coal and natural gas power generation.

The GHG emission intensity of individual generating facilities - which also differ widely - will determine the average GHG emission intensity in a given province. The transparency of generation in Alberta's competitively 


\section{Box 1: Output-based Pricing for Electricity under Alberta's CCIR}

Under Alberta's Carbon Competitiveness Regulation (CCIR), large emitters receive output-based allocations (OBAs) based on the output of a product multiplied by a benchmark emissions intensity for that particular product. For example, cement manufacturers receive a credit of 0.7853 tonnes of $\mathrm{CO}_{2}$ equivalent for each tonne of cement, thus reducing their total carbon costs. For most products, the Alberta benchmark is 80 percent of production-weighted average emission intensity for the given product - although other products' benchmarks are adjusted based on trade exposure (Alberta 2018). While crediting each unit of a product with a benchmark-based OBA lowers the average carbon costs, a producer still has a profit-driven incentive to shift production towards facilities with lower emissions intensity and for facilities to adopt best-in-class technology (See online Appendix A for an exposition).

Alberta's electricity benchmark is based on the GHG emissions intensity of 370 tonnes of $\mathrm{CO}_{2}$ equivalent/GWh for generation by a best-in-class combined cycle natural gas turbine ("good as best gas"). The CCIR also prescribes an annual 1 percent tightening of the benchmark starting in 2020. Importantly, renewable generation facilities may opt-in to Alberta's CCIR regime and receive OBAs at the benchmark rate, provided that the facility does not already receive incentives or subsidies under a separate program (see paragraph 4(11) (b) of the CCIR). For example, wind power with fixed-price contracts under Alberta's Renewable Electricity Program are ineligible for output-based allocations under the CCIR.

The rationale for OBAs is to address competitiveness concerns for trade-exposed sectors - that is, Canadian producers who lose out to foreign competitors in jurisdictions that have lower or no carbon pricing (Beugin 2017). In concept, OBAs aim to level the playing field with these foreign competitors.

However, the competitiveness rationale does not hold for power generation, for which trade exposure is relatively low. Despite relatively minimal exports and imports of electricity in Alberta (together approximately 2 percent of overall demand in 2016), power generation facilities also receive OBAs. The decision to assign OBAs to power producers appears to be motivated by distributional concerns rather than economic efficiency. Alberta's Climate Change Leadership Panel recommended that power generation facilities receive OBAs to have "fewer carbon costs being passed through to electricity consumers. (Alberta's Climate Change Advisory Panel 2015 at p.48)" That is, OBAs for power generators avoid imposing the full carbon costs of electricity on consumers. This reduces consumers' incentive for conserving electricity and departs from the principle of internalizing the economy-wide costs of GHG emissions in individual decisions (Dion 2018).

Instead, in order to mitigate the impacts of power prices on households, a government could charge power producers the full carbon price but recycle these revenues to households through direct transfers (as the federal government has chosen to do with fuel charge revenues through Climate Action Incentive Payments). While various trade-exposed industries are major power users, crediting electricity producers with OBAs for all power generated is over-inclusive: even if power producers faced the full carbon price, a government could specifically imbed an electricity component into OBAs for specific trade-exposed sectors (i.e., incorporate a benchmark GHG emission intensity for electricity and for the sector's power usage in the benchmark emission intensity for the given sector). 


\section{Figure 2: Fuel Source for Electricity Generation 2017 by Province}

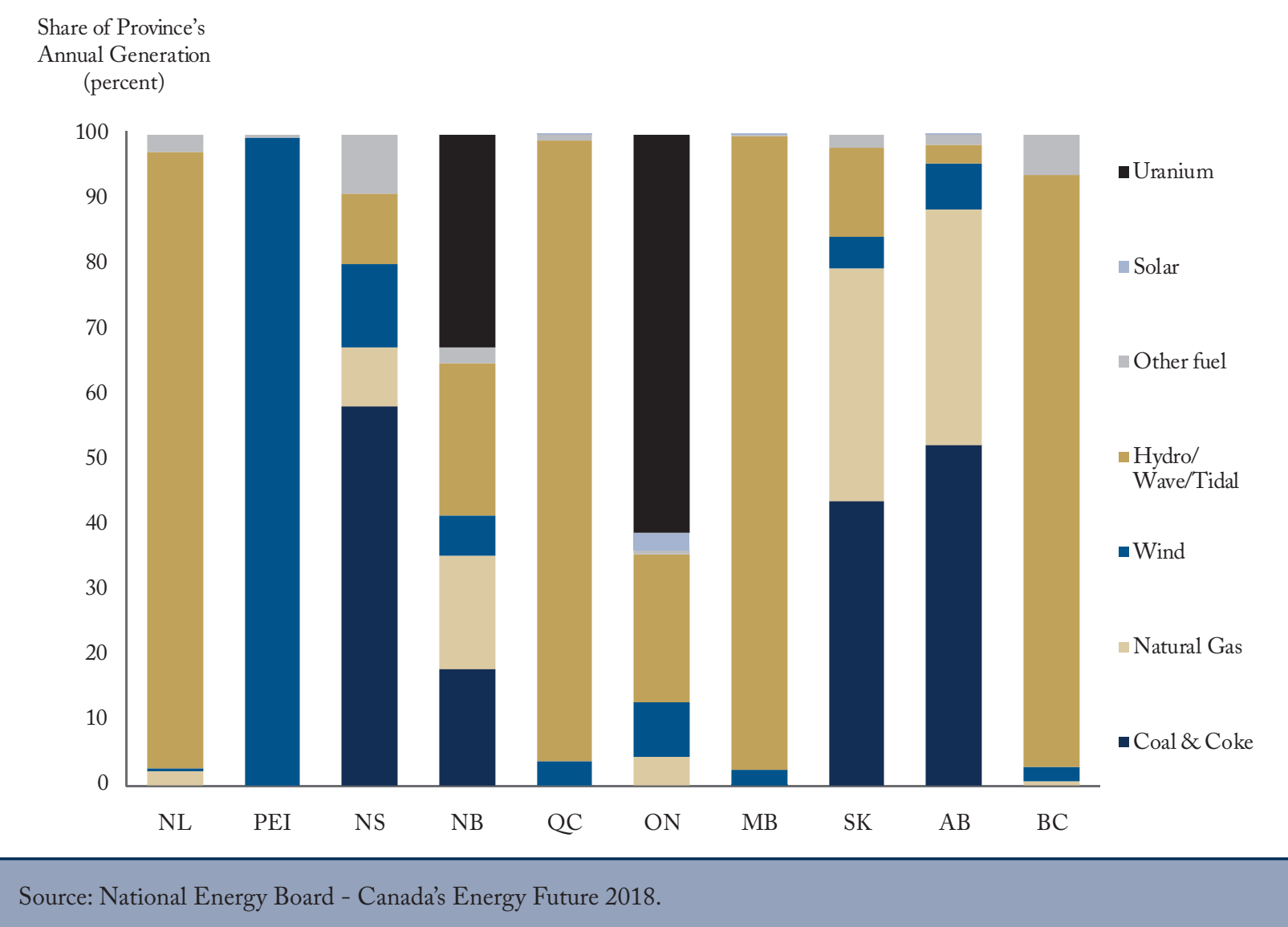

structured power market provides a window into the differences in $\mathrm{GHG}$ emission intensity among the different facilities. ${ }^{4}$

Figure 5 illustrates the estimated GHG emission intensity of individual coal and natural gas power generation facilities in Alberta for 2016 (the latest year for which ECCC has published data). The horizontal axis in Figure 5 provides the cumulative generation by these coal and natural gas facilities during 2016, showing the relative GWh generated by the given facility. The estimated GHG emission intensity of natural gas plants ranges from 370 tonnes/GWh to nearly 700 tonnes/GWh. As well, certain coal-fired plants achieve as low a GHG emission intensity as 950 tonnes/GWh while other coal plants are above 1,100 tonnes/GWh.

4 The GHG emission intensity for individual power facilities in the province can be estimated by combining data on generation by facility from the Alberta Electricity System Operator and the reported facility-specific GHG emissions from ECCC data. The author has estimated the emissions intensity for specific power generation facilities in Alberta using annual metered volumes for 2016 from the Alberta Electricity System Operator's Energy Trading System (AESO ETS, available online: http://ets.aeso.ca/) and greenhouse gas facility reporting data from Environment and Climate Change Canada (ECCC Facility GHG Reporting, available online at: https://www.canada.ca/en/environment-climatechange/services/climate-change/greenhouse-gas-emissions/facility-reporting.html). 


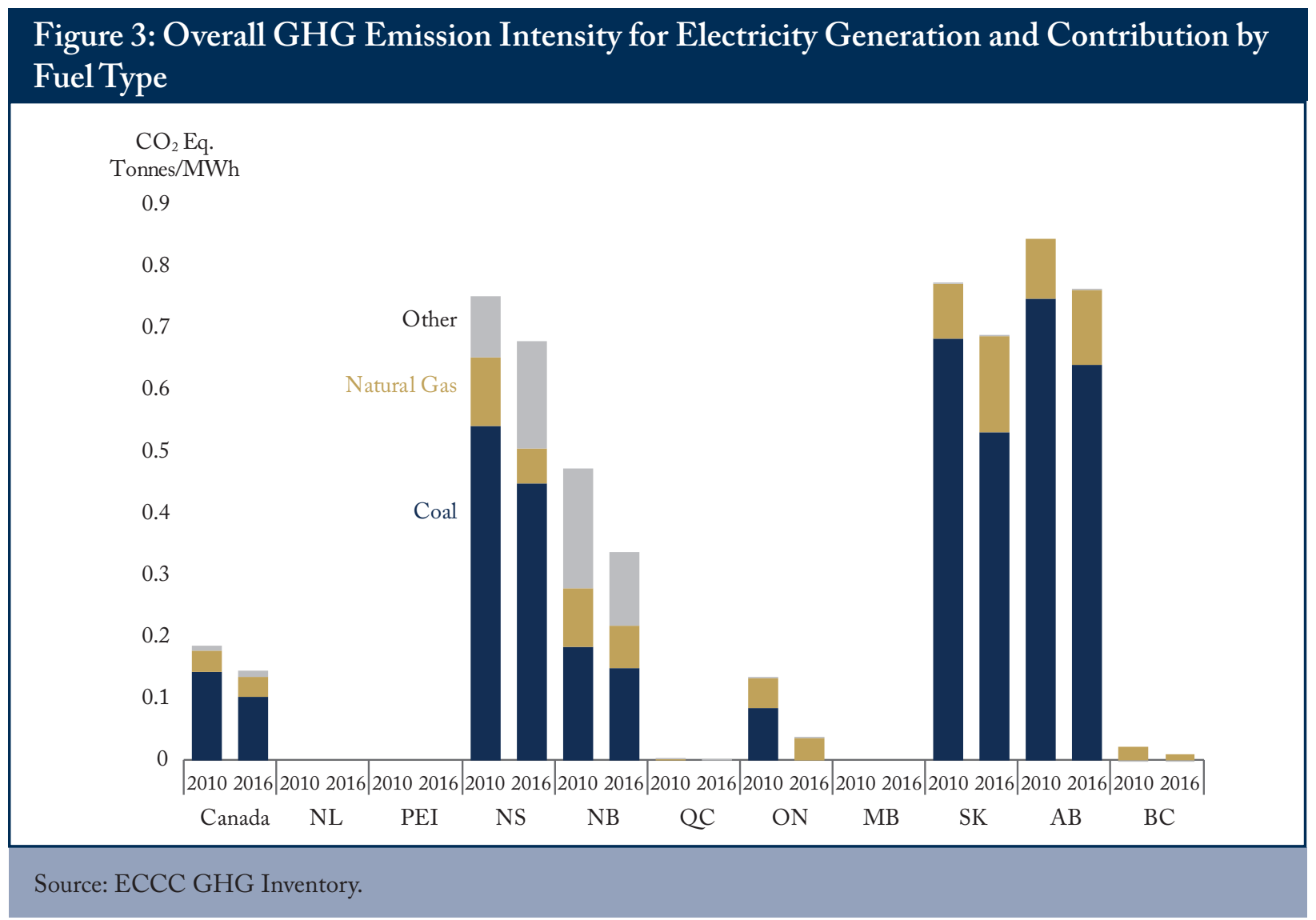

\section{Figure 4: Average GHG Emission Intensity of Coal and Natural Gas Power Generation for Selected Provinces in 2016}

GHG Emission

Intensity Tonnes

$\mathrm{CO}_{2}$ Eq./MWh

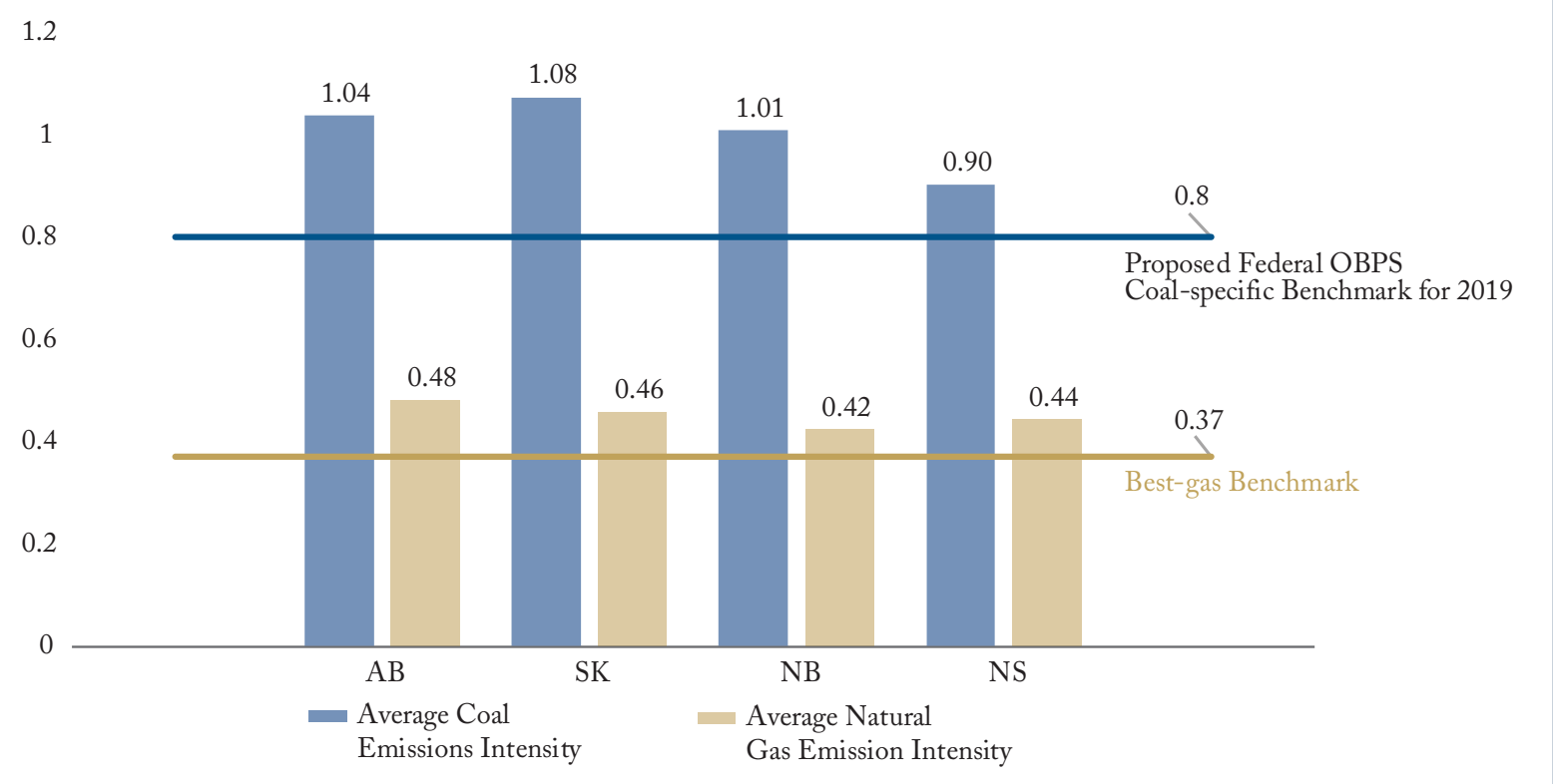

Source: ECCC GHG Inventory. 


\section{Figure 5: 2016 GHG Emission Intensity across Select Alberta Coal and Natural Gas Power \\ Generation Facilities}

Emissions Intensity

Tonnes $\mathrm{CO}_{2}$

Eq./MWh

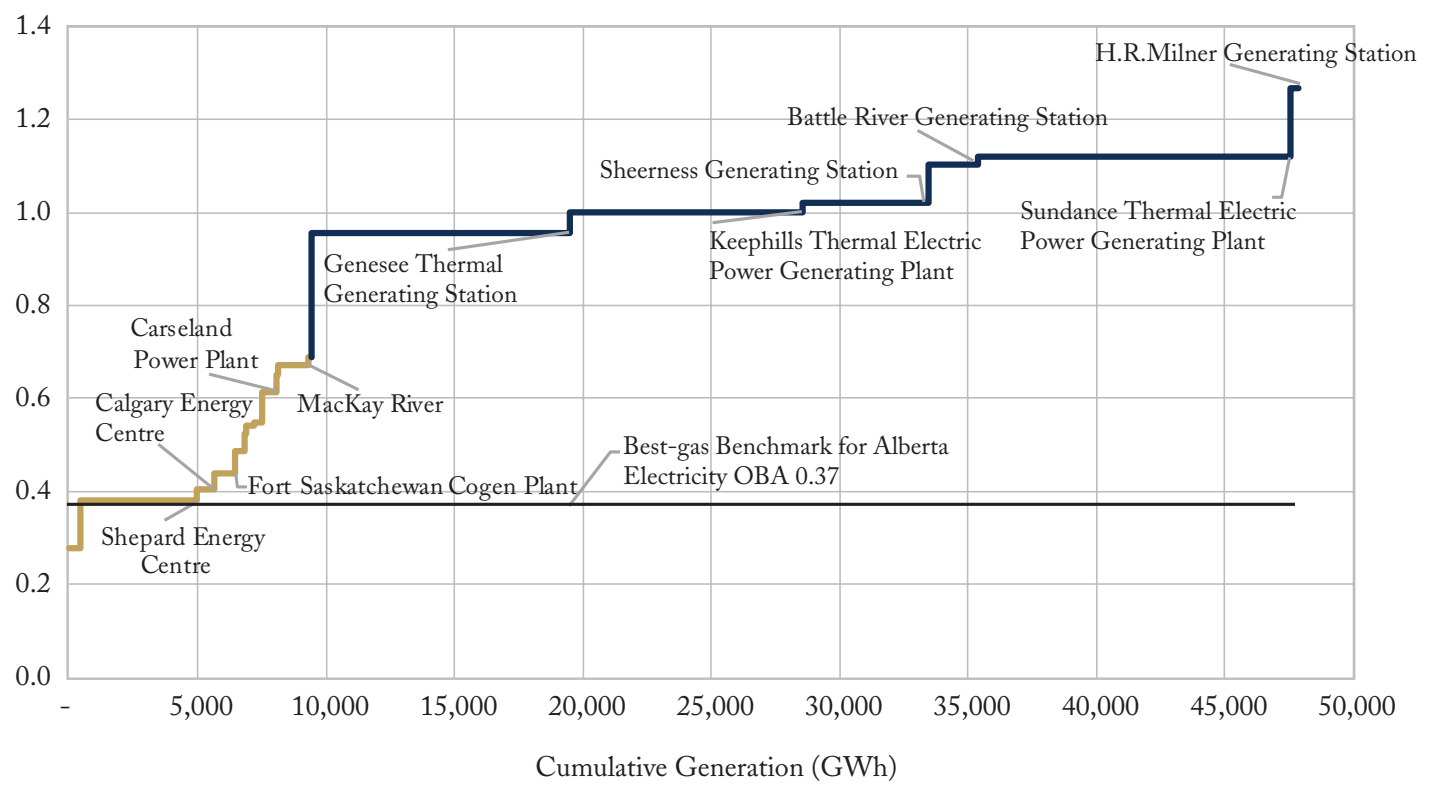

-Natural gas plants —Coal plants _ Best-gas Benchmark for Alberta Electricity OBA

Note: Omits co-generation and industrial generation facilities for which ECCC GHG Inventory does not provide GHG emissions specific to power generation.

Source: AESO ETS, ECCC Specified Emitter GHG Inventory, author's calculations.

\section{The Impact of a Fuel-specific Benchmark on Carbon Costs for Electricity Generators}

Under a uniform benchmark for output-based carbon pricing of electricity (such as that in Alberta), all power producers receive output-based allocations based on a single "best-gas" benchmark for GHG emission intensity. The average carbon cost facing a given power facility will therefore be proportional to the difference between the facility's GHG emission intensity and the benchmark emission intensity. Importantly, since zero-emission forms of generation (e.g., hydro) also receive output-based allocations (OBAs) under Alberta's CCIR, renewable power facilities stand on a level playing field with GHG-emitting generation.

The output-based allocation reduces the carbon cost per tonne facing power producers relative to the carbon price without any allocation. Online Appendix A details how output-based allocations reduce the average carbon costs faced by a facility and impact an operator's offer of power for dispatch. Notably, even with OBAs, producers will still internalize the carbon price in long-run decisions about developing new facilities or implementing a technology that lowers emissions intensity. ${ }^{5}$ Appendix A also illustrates that OBAs will not distort the decision to invest in new technology to reduce a plant's GHG emission intensity. 
Nonetheless, in the short-run decision of whether or not to dispatch an individual asset for generation, emissions intensity is practically fixed. ${ }^{6}$ The average carbon cost per tonne for the given facility is the relevant consideration for the price at which an operator offers power and the decision to dispatch that generation.

As an example, consider a natural gas power facility that emits $500 \mathrm{CO}_{2}$ equivalent tonnes of $\mathrm{GHG}$ per $\mathrm{GWh}$ of electricity and that faces a $\$ 30 /$ tonne carbon price. Crediting OBAs at 370 tonnes/GWh will result in a lower carbon cost per tonne: if the plant generates $1 \mathrm{GWh}$ of electricity, it will have emitted 500 tonnes of GHGs but will also receive a credit for 370 tonnes. Therefore, its carbon cost for this GWh of power - and its corresponding 500 tonnes of emissions - will be:

$$
\begin{aligned}
\text { Carbon price } & \times\left(\frac{G H G \text { emissions }-O B A s}{G H G \text { emissions }}\right)=\$ 30 / \text { tonne } \times\left(\frac{500 \text { tonnes }-370 \text { tonnes }}{500 \text { tonnes }}\right) \\
& =\$ 7.8 / \text { tonne }
\end{aligned}
$$

Under a uniform benchmark GHG emission intensity, a facility's carbon costs will nonetheless therefore be proportional to its difference from that benchmark - regardless of the fuel it uses to generate power. A coal plant that emits 900 tonnes/GWh will face greater carbon costs per tonne than the natural gas facility with a 500 tonnes/GWh emission intensity.

However, differentiating the benchmark between fuel types will reduce the carbon costs per tonne of the coal facility - and indeed may result in certain coal plants facing a lower carbon cost per tonne than lower-emission natural gas plants. To see this, consider the estimated average carbon costs that will face individual coal and natural gas plants in Alberta for 2019 under Alberta's Carbon Competitiveness Incentive Regulation (CCIR) and a \$30/tonne carbon price as exhibited in Figure 6. Under Alberta's uniform benchmark of \$370/tonne, higher emission coal plants will face greater carbon costs than lower emission natural gas plants.

In contrast, compare the estimated carbon costs under the uniform benchmark with those under the proposed federal OBPS for 2019 where plants will face a $\$ 20 /$ tonne carbon price and coal plants would receive output-based credits at 800 tonnes/GWh. The estimated carbon costs for 2019 and 2020 under the federal OBPS for Alberta natural gas and coal power plants (based on these facilities' 2016 GHG emission intensity) are exhibited in Figure 7. As illustrated, despite the higher GHG emission intensity of coal, many coal plants would actually face lower estimated carbon costs per tonne than other lower emission natural gas plants.

Indeed, under the federal OBPS for 2019, coal generation in many provinces may face lower average carbon costs per tonne than natural gas generation. Average carbon costs for coal and natural gas under the federal OBPS can be estimated based on the 2016 average emission intensity for coal and natural gas generation by province (as illustrated above in Figure 4). Figure 8 illustrates the estimated carbon costs per tonne in 2019 under the federal OBPS for selected provinces. As well, Figure 8 exhibits the estimated carbon costs per tonne that coal plants in these provinces would face if subject to a uniform benchmark.

5 See: Andrew Leach (2012) Canadian Tax Journal, 60(4), p.881-98. Available online at: https://www.ualberta.ca/-/me $\mathrm{dia} 167515 \mathrm{D} 24 \mathrm{FBC} 4 \mathrm{AE} 59 \mathrm{D} 74107 \mathrm{CDF} 4052 \mathrm{E} 7$.

6 Plants may be able to improve their heat rate and GHG emission intensity by optimizing operations (e.g., the capacity factor at which the plant operates). 


\section{Figure 6: Estimated 2019 Carbon Costs* for Select Alberta Coal and Natural Gas Power} Generation Facilities** under Alberta CCIR

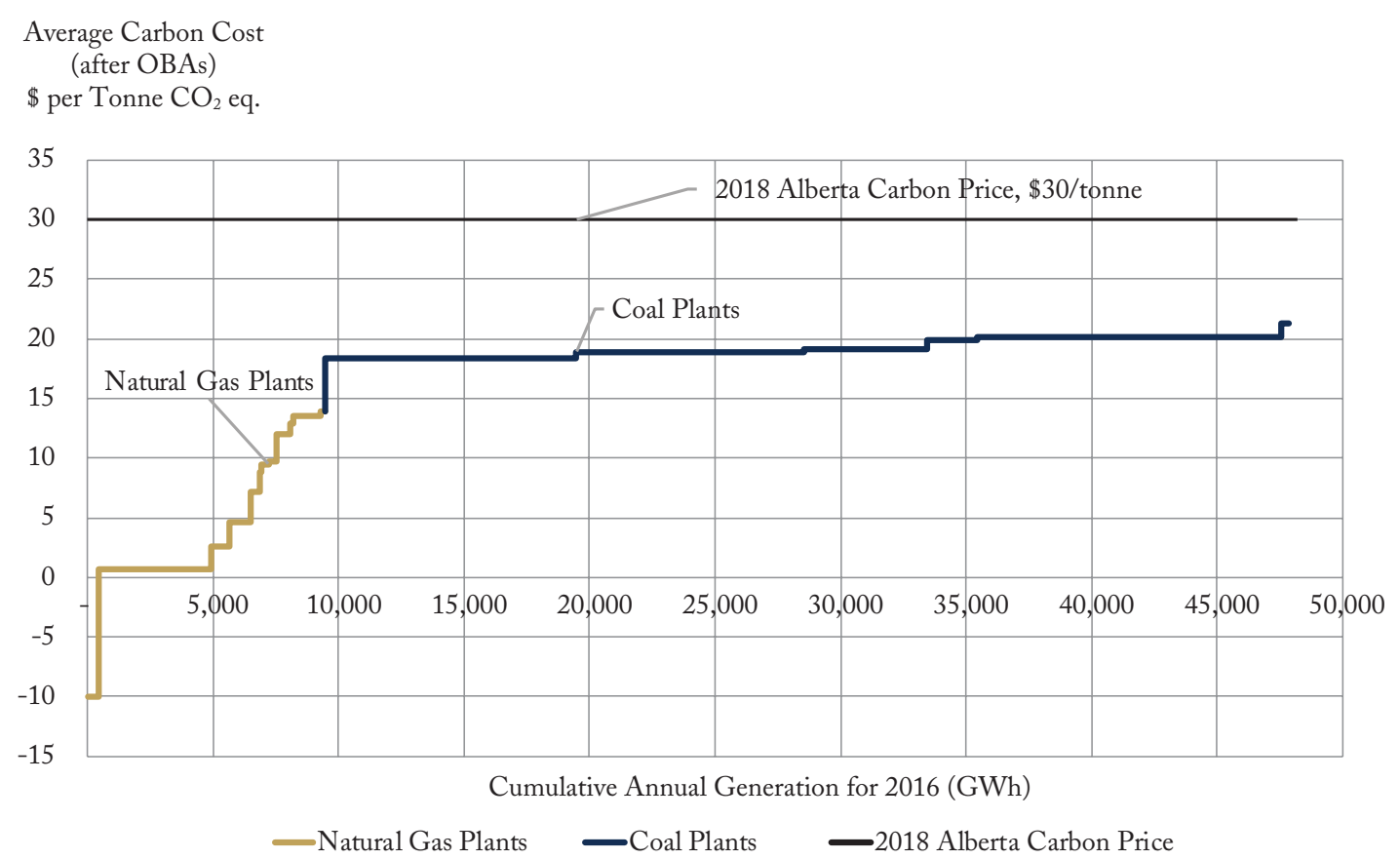

Notes:

* Average carbon price is calculated as explained in technical appendix.

** Omits co-generation and industrial generation facilities for which ECCC GHG Inventory does not provide GHG emissions specific to power generation.

Source: AESO ETS, ECCC Specified Emitter GHG Inventory, author's calculations.

Under the proposed federal coal-specific benchmark of 800 tonnes/GWh for 2019, coal generation in Alberta and Nova Scotia would face average carbon costs per tonne less than natural gas generation in those provinces. In contrast, under a uniform best-gas benchmark, coal generation would face average carbon costs per tonne greater than natural gas generation - reflecting the higher GHG emission intensity of this coal power.

The planned phase-out of coal-specific benchmark in the federal OBPS will gradually increase the average carbon costs per tonne for coal generation over the next decade. Figure 9 exhibits the estimated carbon costs for coal and natural gas generation in Alberta under the Alberta CCIR and proposed federal OBPS.

By 2020 under the proposed federal OBPS, the average carbon costs for Alberta coal generation facilities should increase above those for average natural gas facilities under the current Alberta CCIR. However, under the proposed federal OBPS, natural gas generation will still not be on a level playing field with coal until 2030. Until both coal and natural face the same benchmark emission intensity in 2030, the relative carbon costs will not fully reflect the much higher GHG emission intensity of coal generation. Moreover, as shown in Figure 9, the federal OBPS approach would dramatically reduce carbon costs per tonne for coal relative to those under 


\section{Figure 7: Estimated 2019 and 2020 Carbon Costs* for Select Alberta Coal and Natural Gas Power Generation Facilities** under Proposed Federal OBPS}
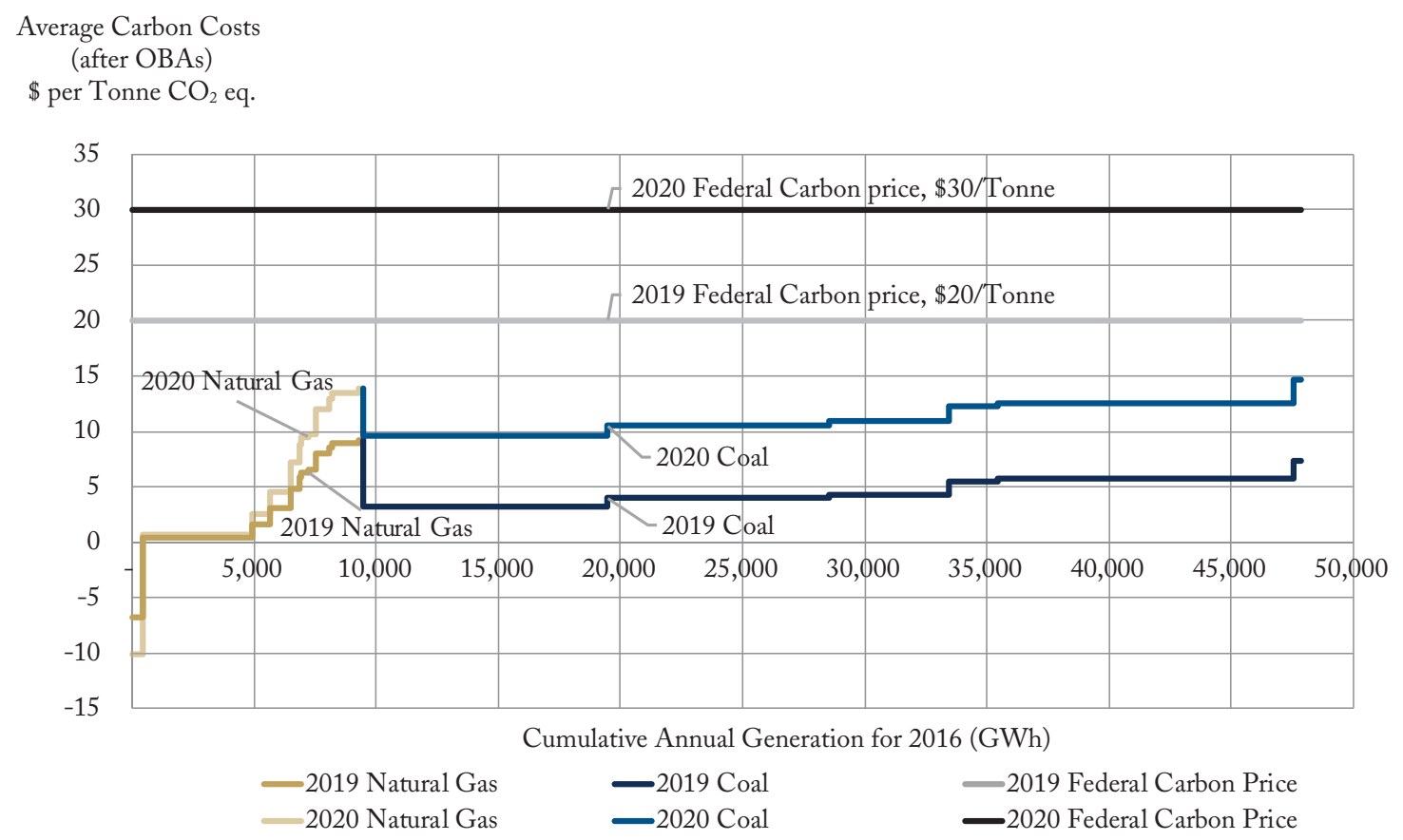

Notes:

* Average carbon price is calculated as explained in technical appendix.

** Omits co-generation and industrial generation facilities for which ECCC GHG Inventory does not provide GHG emissions specific to power generation.

Source: AESO ETS, ECCC Specified Emitter GHG Inventory, author's calculations.

Alberta's present CCIR. It is this "wedge" from the proposed fuel-specific federal OBPS that risks distorting both the dispatch order for power facilities and the investment incentives for renewables.

\section{Fuel-specific Standard May Distort Dispatch Order}

By reducing carbon costs for coal facilities, the proposed federal coal-specific OBPS benchmark risks distorting the order in which plants are dispatched, resulting in higher-emission coal facilities being inefficiently dispatched ahead of lower-emission natural gas facilities. In contrast, by ensuring that facilities with higher GHG emission intensity face higher carbon costs, a uniform best-gas benchmark will not distort the order that facilities are dispatched.

In a competitive real-time power market like that in Alberta, the order of offers into the power pool determines the generation that will be dispatched by the system operator to fulfill demand (the so-called "merit order" or "dispatch" curve). The power price at a given point in time is determined by the best available offer to fulfill demand. The transparency and market-based design for wholesale generation in Alberta provides a 
Figure 8: Average Carbon Costs for Coal and Natural Gas Generation for Selected Provinces under Proposed Federal OBPS in 2019

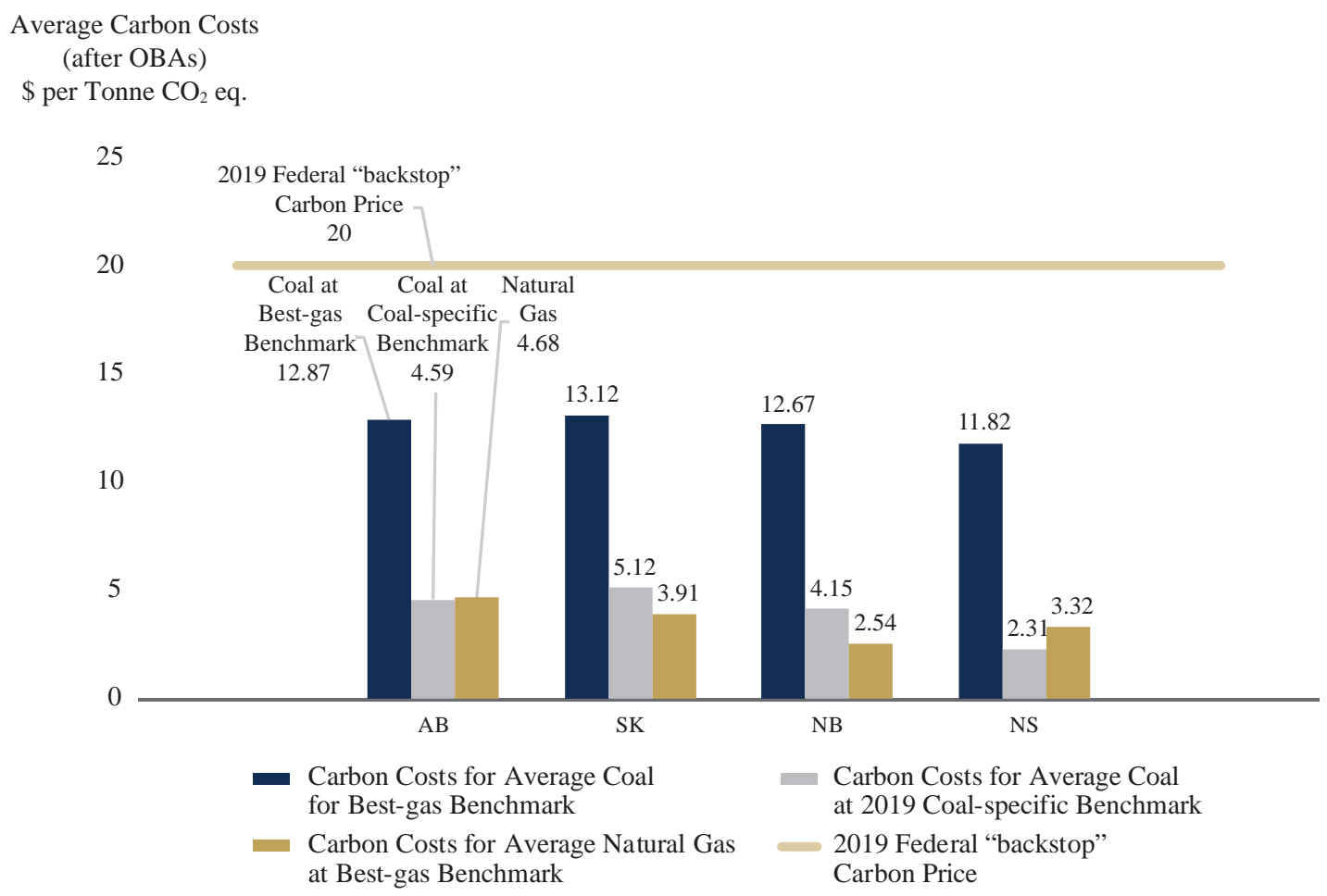

Source: ECCC GHG Inventory, author's calculation.

useful window to the economics for dispatching power generation capacity to fulfill demand from electricity consumers. Figure 10 exhibits the average capacity offered by generating facilities into Alberta's power pool on a sample day, July 16, 2017, showing the fuel type for power available at a given price. The figure shows how blocks of generation capacity are "stacked" in order of the price at which the facility offers power for dispatch. The horizontal axis provides the cumulative MW available at the given price (on the vertical axis). A single facility may offer different blocks of power.

As shown, the price for offers of power climbs steeply at higher levels of demand. The figure shows the different fuel types that would be dispatched, or made available on demand, at increasing levels of demand and the corresponding higher prices. In general, these offers should reflect the operators' marginal cost of generating the blocks of power. ${ }^{7}$ Wind power will be offered into the market at a zero price, since wind assets will be dispatched when wind is available. Certain hydro facilities may be run-of-river and therefore offered at zero prices, but other hydro capacity will be rationed based on the limited water available, with the operator

7 An explanation of the supply characteristics of Alberta' power market is provided by the Alberta Market Surveillance Administrator (2010) Alberta Wholesale Electricity Market. Available online at: https://albertamsa.ca/uploads/pdf/ Reports/Reports/Alberta\%20Wholesale\%20Electricity\%20Market\%20Report\%20092910.pdf. 


\section{Figure 9: Estimated Carbon Costs for Average Coal and Natural Gas Generation in Alberta under Alberta CCIR and Proposed Federal OBPS}

\section{A verage Carbon Costs (after OBAs) \\ $\$$ per Tonne $\mathrm{CO}_{2}$ Eq.}
60
Post-2022 A ssumed \$50/Tonne
Carbon Price

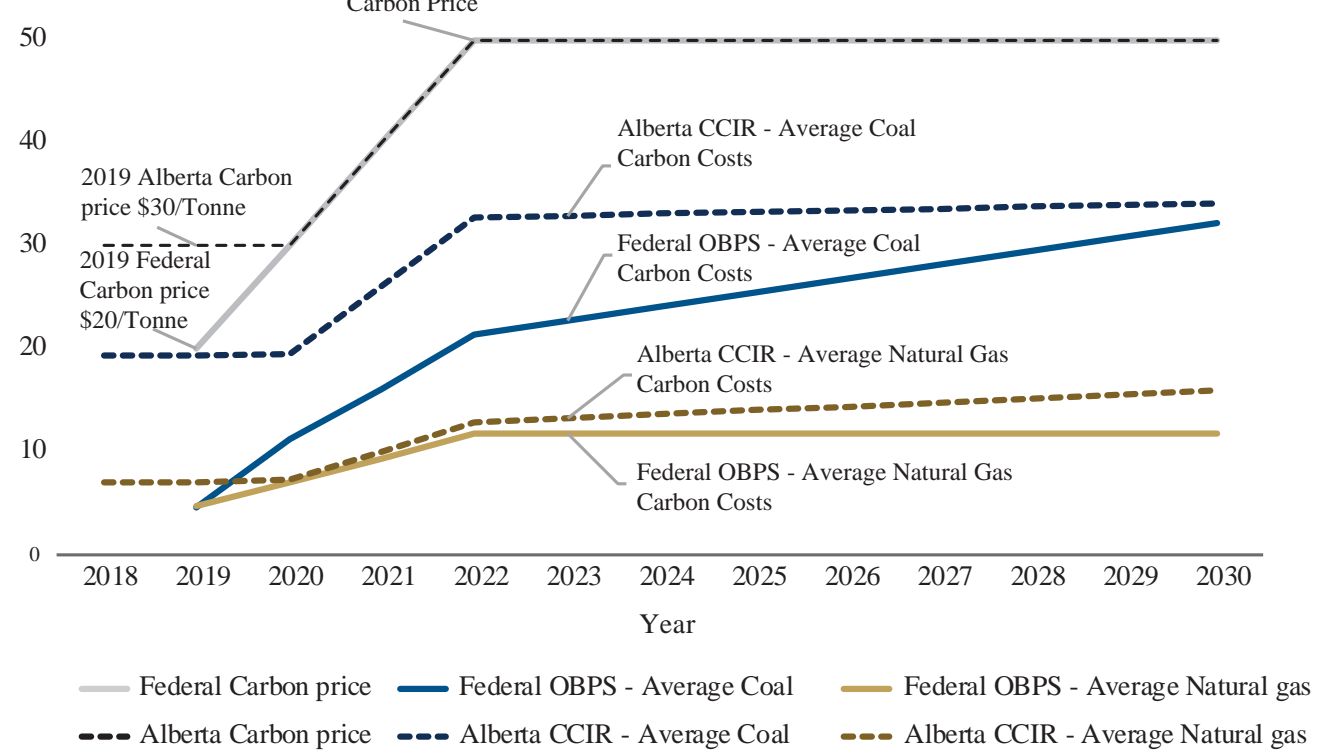

Source: ECCC GHG Inventory, Alberta CCIR, Federal OBPS Regulatory Proposal, author's calculations.

offering this power at a price that reflects the expected opportunity cost of dispatching the limited resource at a future point in time. As well, significant amount of natural gas power (particularly from cogeneration facilities), is offered at low or zero prices, reflecting the "must run" character of these facilities. Furthermore, coal power plants have minimum levels of safe operation and long ramp-up/ramp-down times such that, once the coal plant is ramped up, the operator faces costs for cycling the plant. Much of the available coal power is therefore offered at a zero price. However, higher prices for other offered blocks of coal and natural gas power reflect the costs for ramping up this additional generation. As well, simple cycle natural gas plants will provide rapidly dispatchable peaking capacity but have higher costs.

In the short-run, any power plant will practically have a fixed emissions intensity: absent new investment, generating power will use a fixed generation technology. ${ }^{8}$ With capital and technology fixed in the short-run, an operator's decision to dispatch power will be a function of the facility's average carbon cost. In a competitive

8 In the long-term, an operator may make investments in new capital that improves the plant's emissions intensity - and the economy-wide carbon price will determine the operator's incentive to undertake those investments. Appendix A details this incentive, illustrating how an operator's decision to invest in new technology that lowers emissions intensity is a function of the economy-wide carbon price multiplied by the improvement in emissions intensity. 


\section{Figure 10: Average Generation Capacity and Prices Offered into Alberta's Energy Market on} July 16, 2018 by Fuel Type

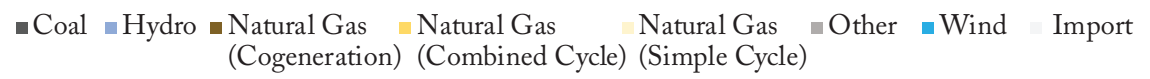

Avg. Offer Price

$\$ / \mathrm{MWh}$

1,000

900

800

700 600

500

400 300

200

100

0

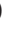
10 5

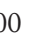
20

100
Min. demand Avg. demand Max. demand 8,627 MW 9,953 MW 10,880 MW

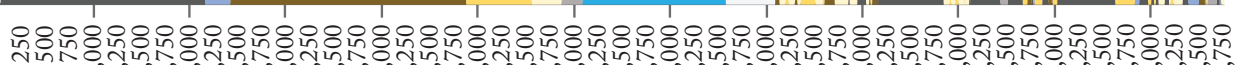
tivinivinmmm

Cumulative MW

Source: Alberta Electricity System Operator.

power market, any operator should offer power into the power pool at its marginal cost for producing power. For a power plant that generates GHG emissions but that receives OBAs at benchmark emissions intensity, an operator's offer into the power pool will be a function of its unit operating costs and the average carbon costs the generation facility faces (i.e., after OBAs). Appendix A illustrates an operator's profit decision for offering power into the power pool. Online Appendix B illustrates the impact of the output-based allocations on the ordering of dispatch.

Importantly, although the average carbon cost for a facility determines the operator's offer into the power pool, the order of offers will be efficiently ordered provided every operator faces the same average carbon cost. However, any differentiation of the benchmark emissions intensity for assigning OBAs would potentially distort the order of offer - for example, if a coal operator faces a lower average carbon cost, then that coal plant may be offered into the power pool at a lower price than a natural gas generator. Appendix B provides a hypothetical example to exhibit this distortion.

\section{Federal OBPS Dampens the Incentive for New Renewables}

Unlike the treatment of electricity under Alberta's CCIR, the proposed federal OBPS will not credit zero-emission generation with output-based credits. The equivalent treatment of zero-emission generation is important for output-based carbon pricing to not distort decisions at the "investment margin." That is, crediting renewable generation for their electricity output avoids distorting investment towards more GHG-intensive forms of 


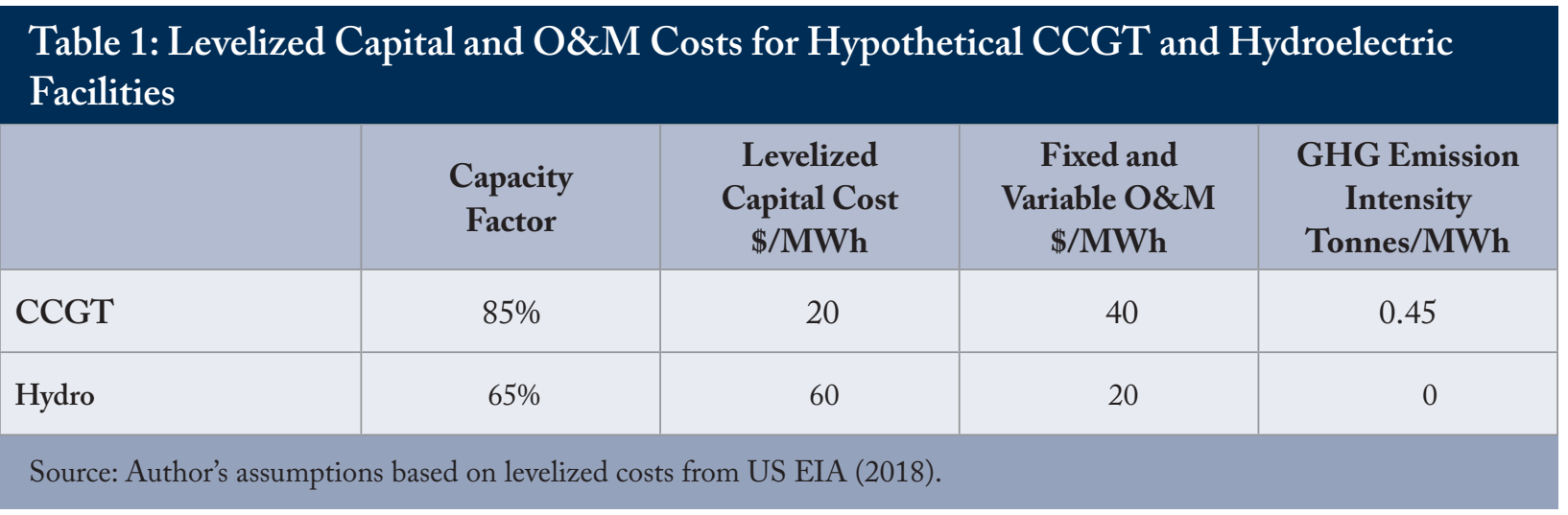

generation. Relative to output-based carbon pricing with a uniform benchmark that applies to all electricity producers, the lack of output-based credits for renewables tilts the playing field towards facilities that emit GHGs and receive output-based credits. If output-based carbon pricing is to be neutral with respect to new investments, facilities that produce the same product but avoid emissions must be treated equivalently.

To see this, consider an investment decision between building a combined-cycle natural gas turbine (CCGT) power plant and a hydroelectric facility with hypothetical levelized costs for the capital investment and for operations and maintenance (O\&M) provided in Table 1. ${ }^{9}$ The example CCGT is assumed to have a GHG emission intensity of 450 tonnes/GWh (or 0.450 tonnes/MWh) while the hydro plant is zero-emission.

When evaluating the respective investments under the proposed federal OBPS, an investor could likely assume a carbon price of $\$ 50 /$ tonne across the lifetime of the investment (reflecting the planned post-2022 federal carbon price). Figure 11 shows the levelized cost of electricity (LCOE) for the example CCGT and hydroelectric facilities once factoring in the carbon costs. The figure also illustrates the LCOE for the cases where renewables receive OBAs (i.e., under Alberta's CCIR) and do not receive OBAs (i.e., under the proposed federal OBPS).

At its 0.450 tonne/MWh GHG emission intensity and this $\$ 50 /$ tonne carbon price, the CCGT would pay $\$ 22.50$ / MWh for its GHG emissions. Note that, facing a carbon price but without any output-based allocation, the CCGT would face a $\$ 82.50 / \mathrm{MWh}$ levelized cost of electricity. However, under the proposed federal OBPS, the CCGT would be credited at the benchmark GHG emission intensity of 370 tonnes/GWh with OBAs equivalent to $\$ 18.50$ / MWh at the $\$ 50 /$ tonne carbon price. The net carbon costs for this CCGT would then be $\$ 4.00 / \mathrm{MWh}$ (or roughly $\$ 8.89 /$ tonne of GHG emissions). The investor would face a levelized cost for an investment in the CCGT of $\$ 64.00 / \mathrm{MWh}$.

In contrast, consider the levelized costs for investing in the hydroelectric facility. This plant will face levelized capital and 0\&M costs totalling $\$ 80.00 / \mathrm{MWh}$. If the hydroelectric plant also receives credits at the benchmark GHG emission intensity of 0.370 tonnes/MWh (as is the case under Alberta's CCIR), such OBAs would equal $\$ 18.50 / \mathrm{MWh}$ and the levelized cost for this plant would be reduced to $\$ 61.50 / \mathrm{MWh}$.

9 While intended as an illustrative example, these figures reflect levelized capital and 0\&M costs for such power generation facilities entering service in 2022 based on estimates by the US Energy Information. See: US EIA (2018) Levelized Costs and Levelized Avoided Cost of New Generation Resources in Annual Energy Outlook 2018. Available online at: https://www.eia.gov/outlooks/archive/aeo18/pdf/electricity_generation.pdf. 


\section{Figure 11: Levelized Cost of Electricity for Hypothetical CCGT and Hydroelectric Facilities}

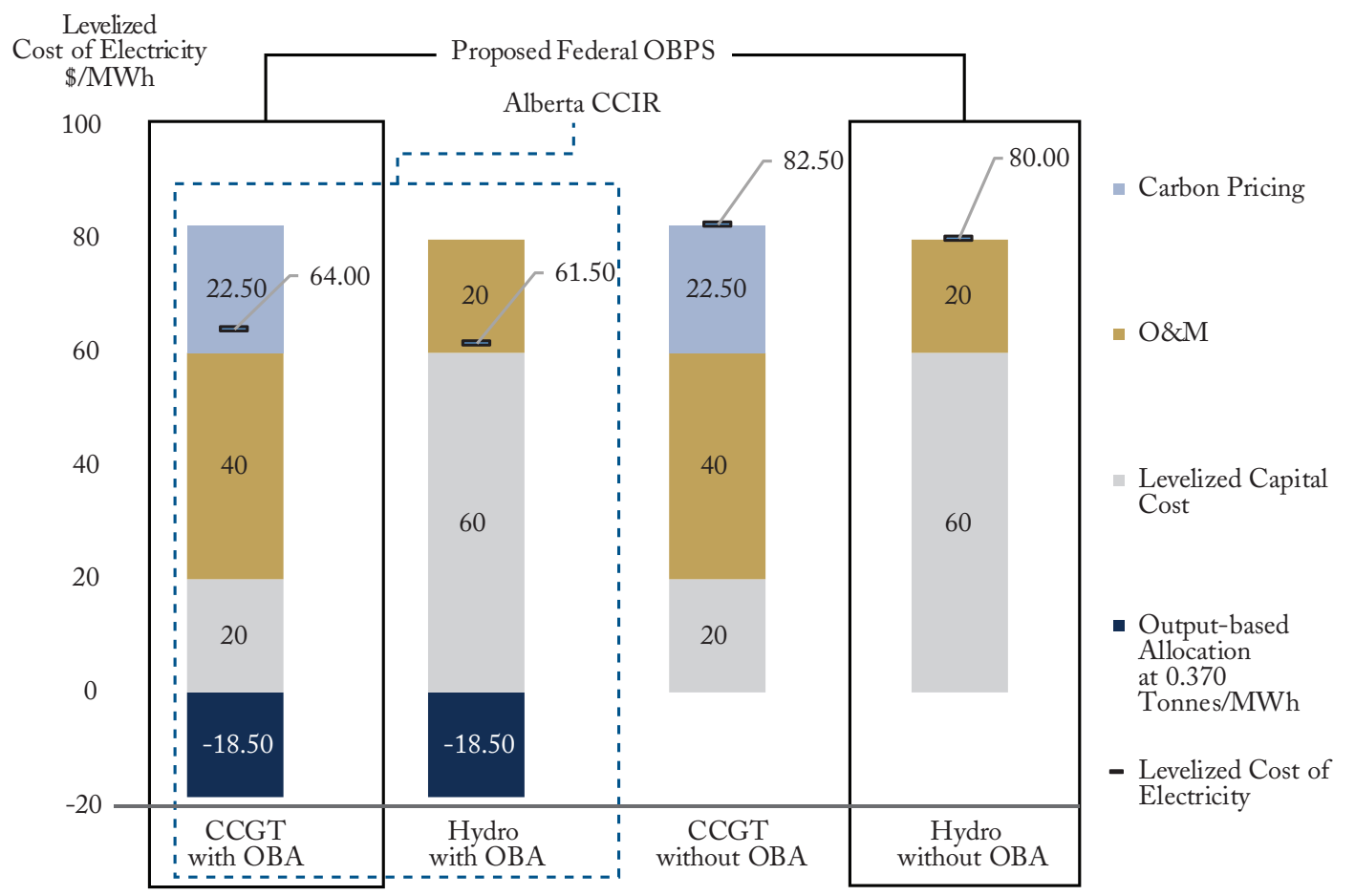

Source: Author's calculations based on levelized costs from US EIA (2018).

The example shows how the proposed fuel-specific federal OBPS would distort the investment decision in renewables. When the full carbon price applies to every electricity producer irrespective of fuel, the example hydroelectric facility would have a cost advantage over the CCGT (i.e., LCOE of \$82.50/MWh for CCGT versus $\$ 80.00 / \mathrm{MWh}$ for hydro). When these facilities are treated equally by crediting each with OBAs, the hydro facility retains this cost advantage ( $\$$ LCOE of $\$ 64.00 / \mathrm{MWh}$ for CCGT versus $\$ 61.50 / \mathrm{MWh}$ for hydro). However, the deck is stacked against the hydro plant under fuel-specific benchmark in the proposed federal OBPS. Since only the CCGT receives OBAs, the hydro facility will face a LCOE of $\$ 80.00$ against a LCOE for the CCGT of only $\$ 64.00 / \mathrm{MWh}$.

\section{Conclusion: One Benchmark for One Product}

Imposing fuel-specific carbon prices for power producers risks de-anchoring carbon pricing from any economic principle. The coal-specific benchmark for electricity risks distorting the dispatch curve for power generation, with coal generation potentially preferred over lower-emissions natural gas facilities.

Relative to a uniform benchmark applicable to all generation facilities, the proposed federal OBPS also will discourage investment in renewables. Since zero-emission facilities will not receive output-based allocations under the proposed federal OBPS, investment in GHG-emitting facilities will have a cost advantage over new investments in renewable generation. 
For these reasons, Ottawa should reconsider its fuel-specific benchmark for electricity in its carbon pricing backstop and instead apply a uniform benchmark for output-based allocations for all forms of power generation. If applying output-based carbon pricing to the electricity sector, the federal government should maintain the principle of "one benchmark for one product." 


\section{References}

Alberta. 2018. "Standard for Establishing and Assigning Benchmarks V2.1, Carbon Competitiveness Incentive Regulation” June. See: https://www.alberta.ca/carbon-competitiveness-incentive-regulation. aspx.

Alberta's Climate Change Advisory Panel. 2015. Climate Leadership Report to the Minister. Nov 20. Available online at: https://www.alberta.ca/climate-leadership-discussion.aspx.

Alberta Market Surveillance Administrator. 2010. Alberta Wholesale Electricity Market. Available online at: https://albertamsa.ca/uploads/pdf/Reports/Reports/Alberta\%20Wholesale\%20Electricity\%20 Market\%20Report\%20092910.pdf.

Beugin, Dale. 2017. "Output-based pricing in the real world." Canada's EcoFiscal Commission. Dec. 7. Available online at: https://ecofiscal.ca/2017/12/07/output-based-pricing-in-the-real-world/.

Dion, Jason. 2018. “Do OBAs make sense for the electricity sector?” Canada’s Ecofiscal Commission. May 9. Available online at: https://ecofiscal.ca/2018/05/09/do-obas-make-sense-for-electricity/.

Environment and Climate Change Canada. 2018 Proposal for the Output-Based Pricing System Regulations. December 20. Available online at: https:/www.canada.ca/en/environment-climate-change/services/ climate-change/pricing-pollution-how-it-will-work/output-based-pricing-system/proposalregulations.html.

Environment and Climate Change Canada. 2018. Notice of intent to make regulations under part 2 of the Greenhouse Gas Pollution Pricing Act. Available online: https://www.canada.ca/en/environment-climatechange/services/climate-change/pricing-pollution-how-it-will-work/output-based-pricing-system/ notice-intent.html.

Leach, Andrew. 2012. "Policy Forum: Alberta's Specified Gas Emitters Regulation.” Canadian Tax Journal, 60(4), p.881-98. Available online at: https://www.ualberta.ca/-/media/167515D24FBC4AE59D74107 CDF4052E7.

Shaffer, Blake. 2018. "Canada's new large-emitter pricing system might defeat the carbon tax's own purpose." Nov 5. Maclean's. Nov. 5. Available online at: https://www.macleans.ca/opinion/canadas-newlarge-emitter-pricing-system-defeats-the-carbon-taxs-own-purpose/.

U.S. EIA (2018) Levelized Costs and Levelized Avoided Cost of New Generation Resources in Annual Energy Outlook 2018. Available online at: https://www.eia.gov/outlooks/archive/aeo18/pdf/electricity_ generation.pdf.

This E-Brief is a publication of the C.D. Howe Institute.

Grant Bishop is Associate Director, Research, at the C.D. Howe Institute.

This E-Brief is available at www.cdhowe.org.

Permission is granted to reprint this text if the content is not altered and proper attribution is provided.

The views expressed here are those of the authors. The C.D. Howe Institute does not take corporate positions on policy matters. 